\title{
Escritas de sangue: existir e transgredir nas encruzilhadas das violências
}

Blood Writings: to Exist and to Transgress at the Crossroads of Violence

\author{
Marisangela Lins de Almeida ${ }^{1}$ (iD) 0000-0001-51 10-6022
}

'Universidade Federal de Santa Catarina, Programa de Pós-Graduação em História, Florianópolis, SC, Brasil. 88040-900 - ppghst@contato.ufsc.br

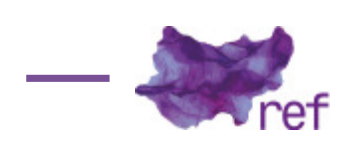

CARNEIRO, Sueli.

Escritos de uma vida.

Belo Horizonte: Letramento, 2018.

Os aspectos de violência perpetrados pela naturalização do racismo na sociedade brasileira estabeleceram espaços e não-espaços para nós, mulheres negras. Nesse sentido, persiste a insistência cultural de pensar as negras como empregadas domésticas ou como mulatas tipo exportação, estereótipos discursivos que nos distanciam do trabalho intelectual.

Sueli Carneiro, uma das vozes negras mais combativas e potentes da sociedade brasileira, executa um duplo enfrentamento a esses estereótipos: o próprio ato transgressor de sua escrita como afirma Conceição Evaristo (2018), para mulheres negras, escrever e publicar são atos políticos - e o conteúdo combativo problematizado enfaticamente em todos os textos que compõem a coletânea Escritos de uma vida, cujo título contempla a historicidade que marca suas reflexões. 0 livro reúne diversos textos, palestras e conferências, realizadas por Sueli Carneiro, desde a década de 1980 até recentemente.

Publicado pela Editora Letramento em 2018, a obra, segundo a própria Sueli Carneiro, é resultado da cobrança de Conceição Evaristo e do voluntarismo de Djamila Ribeiro. Somando 289 páginas divididas em 19 capítulos de extensões variadas, o livro é apresentado por Djamila e prefaciado por Conceição. Sua narrativa é construída a partir do conceito de interseccionalidade, que marca a maioria dos capítulos do volume, e todo seu debate é cruzado por temas relacionados à intersecção entre raça, gênero e classe. A solidão das mulheres negras, a necessidade de desconstruir o Mito da Democracia Racial, de enegrecer a epistemologia e a prática feministas, são temas recorrentes na obra.

O livro traz uma escrita marcada pela sua experiência e vivência como intelectual, mulher negra e doutora em Filosofia (USP). Nascida na década de 1950 em São Paulo, filha de uma costureira e de um ferroviário, foi uma das primeiras mulheres negras brasileiras a ingressar na universidade. A publicação permite lermos uma escrita combativa de uma das mais importantes pesquisadoras sobre feminismo negro e ativista antirracista, cujo nome está relacionado à política de implantação de cotas raciais no Brasil.

Atenta às reflexões de suas antecessoras, Sueli Carneiro honra nossa geração com voz combatente. Inspirada em Lélia Gonzalez, Beatriz Nascimento, Luiza Bairros e em outras intelectuais negras brasileiras e norte-americanas, com quem dialoga, ela aposta num feminismo que possa contribuir com um projeto de sociedade igualitária e democrática. 
Na obra, Sueli Carneiro se propõe compreender as particularidades das opressões que afetam as mulheres negras brasileiras. Já em seu primeiro texto, intitulado "Mulher negra", publicado inicialmente em 1985, analisa a situação socioeconômica e educacional das mulheres negras brasileiras. A partir de dados estatísticos, demonstra o imenso abismo na estrutura ocupacional e de renda entre as populações branca e negra, de forma geral, e a desigualdade entre mulheres brancas e negras nessa mesma estrutura, de forma particular.

Em outro texto, publicado originalmente na Revista Estudos Feministas em 1995, em resposta a um artigo de Joel Rufino e Wilson dos Santos, no qual os autores comparam mulheres negras a Fuscas (fáceis e baratas) e mulheres brancas a Monzas, numa óbvia analogia de que os homens negros que prosperam economicamente "trocam" a mulher negra pela branca, Sueli Carneiro desnuda a desvalorização estética das mulheres negras. Segundo Carneiro (2018), o lugar de onde os autores Joel Rufino e Wilson dos Santos falam é do negro que experimentou ascensão social resgatando sua humanidade através do prestígio ou do dinheiro e, por ter se tornado sujeito, incorporou o direito - assim como o homem branco se dá - de nomear e valorar coisas e pessoas. Nesse sentido, a desumanização das mulheres, negras e brancas, funciona como elemento de afirmação da humanização do homem negro porque o inscreve na lógica masculina dominante. Assim, o machismo seria o espaço de cumplicidade entre homens negros e brancos. Sueli Carneiro explicita que a desvalorização estética das mulheres negras, um dos efeitos da combinação do racismo e sexismo, é resultado do processo histórico de sexualização de seus corpos e da coisificação das mulheres.

Os textos que compõem Escritos de uma vida são transpassados pelo empenho constante da autora na desconstrução do mito da democracia racial brasileira. Na sua compreensão, há uma histórica conspiração de silêncio sobre esse tema. Ela recorre, frequentemente, aos estudos do sociólogo argentino Carlos Hasenbalg para desconstruir a ideia de um paraíso racial:

Para o estudioso Carlos Hasenbalg, o mito da democracia racial se sustenta no Brasil pela ausência aparente de conflito racial, pela inexistência de segregação legal, pela presença de alguns não-brancos nas elites e pela miscigenação racial da população, supostamente indicadora de tolerância racial (CARNEIRO, 2018, p. 114).

Na interpretação de Sueli Carneiro, esses fatores alimentam uma falsa impressão de igualdade e democracia raciais. Em uma interessante palestra proferida durante a Conferência Nacional do Instituto Ethos, ocorrida em junho de 2002 e intitulada "Expectativas de ação das empresas para superar a discriminação racial", ela, a partir de dados concisos, mostra o avesso da tolerância racial. A fragilidade da democracia racial se evidencia ao apontar algumas conclusões: há um processo de extermínio de crianças e adolescentes negras/os no Brasil; há desigualdades nas decisões judiciais (pessoas negras e brancas sofrem penas diferentes para mesmos crimes); mulheres negras são vítimas de projetos de esterilização em massa; a expectativa de vida das pessoas negras é, em média, cinco anos menor que a de brancas, chegando a doze anos, dependendo da região do país.

Segundo aponta, esses aspectos revelam formas-limite do racismo no Brasil. Isso quer dizer que a violência racial possui uma face mais sutil, porém não menos violenta, pois consiste na sistemática criação e reprodução de desigualdades entre pessoas brancas e negras, manifestando-se em todos os aspectos da vida social, produzindo exclusões no acesso à educação, enegrecimento do trabalho infantil, divisão racial das ocupações e rendimentos que obstaculizam esforços de mobilidade social. Ainda na interpretação de Carneiro (2018, p. 124) "quando a desigualdade de raça se alia com a de sexo, constrói-se um verdadeiro 'matriarcado da miséria', que é o que configura a experiência histórica de ser mulher negra na sociedade brasileira". Assim, por exemplo, ela demonstra que o trabalho doméstico é o lugar que a sociedade racista determinou como prioritário para as mulheres negras.

Nesse sentido, de forma cruzada, os textos que compõem a coletânea Escritos de uma vida apontam a importância de políticas públicas que atuem no sentido de desconstruir estereótipos racistas. De modo específico, dois capítulos problematizam tal questão: “'Terra Nostra' só para italianos", artigo publicado na Folha de São Paulo em 1999, escrito em reação às cenas com estereótipos negativos sobre negros e negras na novela da Rede Globo Terra Nostra, cujas mensagens simbólicas - encontradas em diálogos entre personagens, bem como a omissão da violência da escravidão e das resistências a ela - reforçavam construções estereotipadas, tais como a resignação das pessoas negras à escravização (coragem, bravura e orgulho seriam atributos da brancura). Para Sueli Carneiro, a subserviência e o infantilismo das personagens negras reiterariam uma visão de humanidade incompleta do negro. Essa estereotipia justificaria a marginalização e a exclusão históricas da população negra. Em "Gênero e raça na sociedade brasileira", texto originalmente publicado no livro Gênero, democracia e sociedade brasileira, em 2002, Sueli Carneiro se detém na análise das construções históricas de estereótipos da mulher negra. Segundo ela, o estupro colonial está na base de todas as hierarquias de gênero e raça. 
Situando essa análise, a autora dialoga com as considerações da antropóloga e intelectual negra norte-americana Angela Gilliam (1996) que define esse processo como "a grande teoria do esperma da formação nacional" (GILLIAM, 1996, p. 54) através do qual: o papel da mulher negra na formação da cultura nacional é rejeitado; a desigualdade entre homens e mulheres é erotizada e a violência sexual contra as mulheres negras é romantizada.

Analisando o caso brasileiro, Sueli Carneiro afirma que o discurso sobre identidade nacional omitiu a dimensão de gênero e raça. De acordo com a autora, a historiografia pouco se deteve na história da construção do gênero: será a ficção que se encarregará de estabelecer atributos do que é ser mulher e negra na sociedade brasileira. Dessa forma, "A mulher negra será retratada pela ficção como exótica, sensual, provocativa. Enfim, com fogo nato; tais características chegam a aproximá-la de uma forma animalesca, destinada exclusivamente ao prazer sexual" (CARNEIRO, 2018 , p. 155). Persiste, portanto, essa visão que destinará a mulher negra ao sexo, ao prazer, às relações extraconjugais. Em sua reflexão, Sueli utilizará o ditado popular brasileiro instituído pela tradição patriarcal colonial para as mulheres brasileiras: preta para trabalhar, branca para casar e mulata para fornicar que, além de estigmatizar as mulheres de forma geral, introduz contradições na concepção de uma universalidade da mulher brasileira, manifestando as discriminações específicas das mulheres negras. Esse fato, inclusive, leva a autora a questionar as teorias epistemológicas feministas alicerçadas no ideal de uma suposta universalidade feminina.

Essa questão é debatida em seu texto "Mulheres em Movimento", publicado pela primeira vez em 2003, na Revista Estudos Avançados. Apesar de destacar a potência e alcance do Movimento de Mulheres brasileiras, enfatiza que, por longo tempo, o feminismo esteve prisioneiro da visão eurocêntrica e universalizante das mulheres. Decorre disso a incapacidade de reconhecer e considerar as diferenças e desigualdades entre as mulheres, mantendo vozes silenciadas e corpos estigmatizados de mulheres vítimas de outras formas de opressão além do sexismo.

Escritos de uma vida é cruzado pela problemática dos aspectos decorrentes do conceito de interseccionalidade, o que a autora realiza a partir das contribuições teóricas de Lélia Gonzalez e da feminista negra norte-americana Patrícia Hill Collins, que aponta a natureza interligada das discriminações de raça, gênero e classe. Assim como Kimberle Crenshaw, uma importante referência no campo conhecido como teoria crítica racial, Sueli Carneiro chama atenção para o fato de que as mulheres negras tiveram experiências históricas diferenciadas e que isso precisa ser considerado pelos movimentos políticos feministas e reconhecido pelas políticas públicas, pois o peso combinado das estruturas de raça e das estruturas de gênero marginaliza mulheres que estão na base. Por esse motivo, propõe a necessidade de enegrecer o feminismo. Essa problemática é central no posicionamento teórico-político de Sueli Carneiro, que evidencia, de forma irrefutável, os aspectos das diferentes experiências históricas entre mulheres brancas e negras. Em sentido próximo, Joan Scott (1999, p. 27) atenta:

Tornar visível a experiência de um grupo diferente expõe a existência de mecanismos repressores, mas não seu funcionamento interno ou sua lógica; sabemos que a diferença existe, mas não a entendemos como constituída relacionalmente. Para tanto, precisamos dar conta dos processos históricos que, através do discurso, posicionam sujeitos e produzem suas experiências. Não são os indivíduos que têm experiência, mas os sujeitos é que são constituídos através da experiência.

O percurso histórico das reflexões de Sueli Carneiro, tão bem articulado ao longo da obra, é marcado pela vivência de ser mulher negra. Isso se coloca como questão fundamental ao analisarmos as contribuições teóricas de intelectuais negras. Como apontou Kimberle Crenshaw (2002), a questão da interseccionalidade se apresentou para ela a partir de uma experiência pessoal, aliás o processo de compreensão desse fenômeno é marcado também por vivencias das mulheres negras, o que a levou a utilizar-se da expressão "experiências de Interseccionalidade" (CRENSHAW, 2002, p. 9).

Patricia Hill Collins (2016), por sua vez, argumenta que a postura crítica de intelectuais negras marginais é essencial para gerar um ponto de vista diferente em relação aos paradigmas sociais. Enquanto sujeitos do saber, mulheres negras questionam as bases das verdades epistemológicas, inclusive do pensamento feminista dito universal, branco e com bases eurocêntricas. É desse lugar de invisibilidade que Sueli Carneiro teoriza. Aliás, ela argumenta a respeito de como o processo da escrita, advindo do desejo de comunicar indignação frente às injustiças, se tornou um instrumento de combate, respondendo a necessidade de produzir argumentos para confrontos impostos pelo racismo, sexismo e suas combinações.

É a partir de suas experiências cotidianas e acadêmicas que mulheres negras estão teorizando e produzindo uma epistemologia feminista negra. A esse respeito Conceição Evaristo (2009, p. 18), com quem Sueli Carneiro dialoga, afirma: "quando escrevo, quando invento, quando crio a minha ficção, não me desvencilho de um 'corpo-mulher-negra em vivência' e que por ser esse 'o meu corpo, e não outro', vivi e vivo experiências que um corpo não negro, não mulher, jamais experimenta".

Mostrando-se otimista, Sueli Carneiro, em "Gênero e raça na sociedade brasileira", texto 
escrito em 2002, postula que a luta das mulheres negras contra a opressão de gênero e raça vem desenhando novos contornos para a ação política feminista e antirracista.

Por fim, em "Tempo Feminino", texto apresentado no Seminário Tempo Feminino, em 2000, estabelecendo um importante diálogo entre as velhas feministas, como denomina, e as novas gerações, Sueli Carneiro questiona: serão as mulheres brancas das novas gerações parceiras na luta por reparações e ações afirmativas para eliminar desvantagens históricas acumuladas pelos negros em geral e pelas mulheres negras em particular? Para ela, apesar dos avanços conquistados pelas mulheres brasileiras, há lutas que precisam ser travadas pelas novas gerações de mulheres para ampliar e manter essas conquistas.

Os diferentes textos que compõem os Escritos de uma vida, de Sueli Carneiro, apesar de terem sido produzidos em períodos históricos distintos, estão interligados. Manifestam as continuidades do racismo na estruturação das desigualdades na sociedade brasileira. As reflexões apresentadas acompanham a trajetória de enfrentamentos e lutas da autora contra as opressões raciais e de gênero, vivenciadas, literalmente, na própria pele.

Sueli Carneiro nos brinda com profundas reflexões e, entre outros pontos, manifesta a importância e a necessidade de realizarmos recortes raciais, de gênero e classe social em nossas análises. Por isso, a publicação é de fundamental importância para compreendermos as nuances das discriminações interseccionais vivenciadas pelas mulheres negras no Brasil. Nossos passos vêm de longe.

Obrigada, Sueli Carneiro!

\section{Referências}

CARNEIRO, Sueli. Escritos de uma vida. Belo Horizonte: Letramento, 2018.

COLLINS, Patrícia Hill. "Aprendendo com a outsider within: a significação sociológica do pensamento feminista negro". Revista Sociedade e Estado, v. 31, n. 1, p. 99-127, jan./abr. 2016.

CRENSHAW, Kimberle. "Documento para encontro de especialistas em aspectos da discriminação racial relativos ao gênero". Estudos Feministas, v. 10, n. 1, p. 171-188, 2002.

EVARISTO, Conceição. "Em legítima defesa". In: CARNEIRO, Sueli. Escritos de uma vida. Belo Horizonte: Letramento, 2018. p. 07-09.

EVARISTO, Conceição. "Literatura negra: uma poética de nossa afro-brasilidade". Scripta, Belo Horizonte, v. 13, n. 25, p. 17-31, $2^{\circ}$ sem. 2009.

GILLIAM, Angela. In: Anais do Seminário Internacional Multiculturalismo e racismo: o papel da ação afirmativa nos Estados Democráticos Contemporâneos. Brasília: Ministério da Justiça, Secretaria Nacional de Direitos Humanos, 1996.

SCOTT, Joan. "Experiência". In: SILVA, Alcione Leite da; LAGO, Mara Coelho de S.; RAMOS, Tânia Regina Oliveira (Orgs.). Falas de Gênero. Florianópolis: Mulheres, 1999. p. 21-55.

Marisangela Lins de Almeida (mary_lins_18@hotmail.com) possui graduação em História pela Universidade Estadual do Centro-Oeste ē Mestrado em História pela mesma instituição. Doutoranda no Programa de Pós-Graduação em História da Universidade Federal de Santa Catarina (UFSC). Pesquisa temas como gênero, campesinato e populações tradicionais. Doutoranda no Programa de Pós-Graduação em História da Universidade Federal de Santa Catarina (UFSC). 
COMO CITAR ESSE ARTIGO DE ACORDO COM AS NORMAS DA REVISTA

ALMEIDA, Marisangela Lins de. "Escritas de sangue: existir e transgredir nas encruzilhadas das violências". Revista Estudos Feministas, Florianópolis, v. 29, n. 1, e69867, 2021.

CONTRIBUIÇÃO DE AUTORIA

Não se aplica.

\section{FINANCIAMENTO}

O presente trabalho foi realizado com apoio da Coordenação de Aperfeiçoamento de Pessoal de Nível Superior - Brasil (CAPES) - Código de Financiamento 001.

CONSENTIMENTO DE USO DE IMAGEM

Não se aplica.

APROVAÇÃO DE COMITÊ DE ÉTICA EM PESQUISA

Não se aplica.

\section{CONFLITO DE INTERESSES}

Não se aplica.

\section{LICENÇA DE USO}

Este artigo está licenciado sob a Licença Creative Commons CC-BY International. Com essa licença você pode compartilhar, adaptar, criar para qualquer fim, desde que atribua a autoria da obra.

\section{HISTÓRICO}

Recebida em 05/11/2019

Aprovada em 28/02/2020 